\section{Intestinal bowel perforation and bacterial peritonitis secondary to migrated biliary and pancreatic stents}

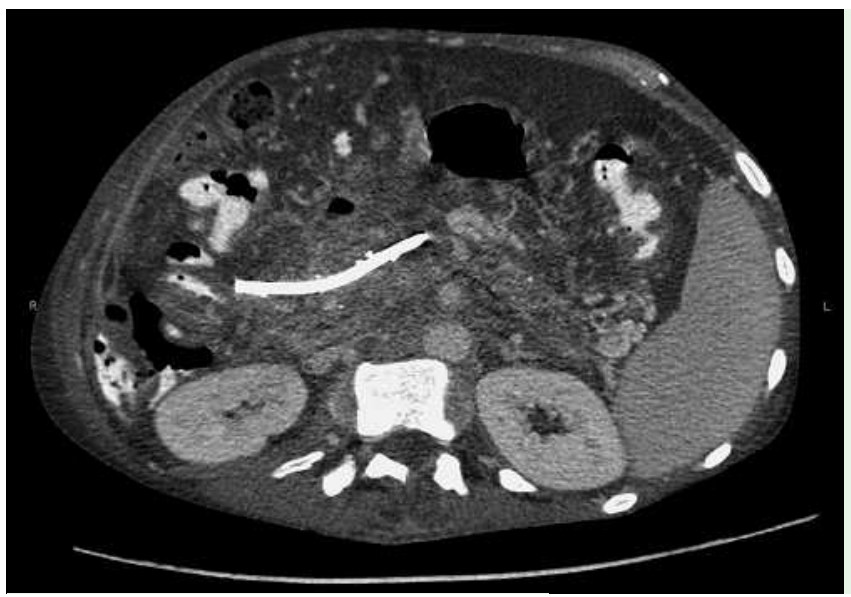

Fig. 1 Curved multiplanar reformation CT image showing a pancreatic stent perforating the duodenum, ascites, intra-abdominal free air, and pancreatic calcifications.

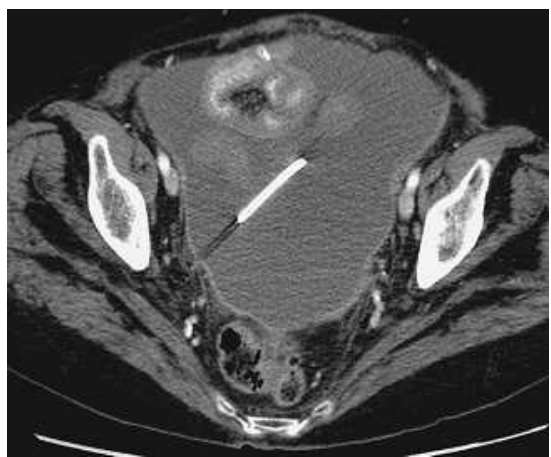

Fig. 2 Abdominal CT showing biliary stent perforating the ileum and ascites.

\section{Case report}

$\nabla$

Intestinal bowel perforation by migrated biliary or pancreatic stent is a rare complication that can occur anywhere in the gastrointestinal tract [1-5]. We report two patients with intestinal perforation and bacterial peritonitis secondary to a migrated stent from the common bile duct and pancreatic duct.

A 43-year-old male with chronic pancreatitis, who underwent an endoscopic cystogastrostomy for a pseudocyst and stenting of the pancreatic duct after extracorporeal shock wave lithotripsy for pancreatic calcifications, was transferred to our institution for treatment of bacterial peritonitis with Streptococcus sp. On admission he was febrile, hypotensive, and had a painful distended abdomen. Blood test revealed leukocytosis and cholestasis. Abdominal computed tomography $(\mathrm{CT})$ scan showed ascites, intra-ab-

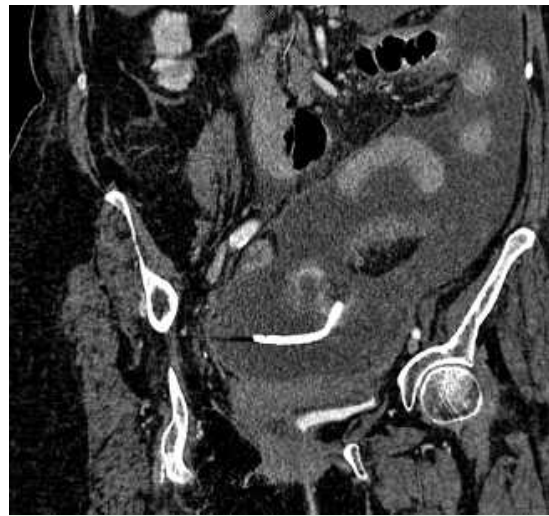

Fig. 3 Curved multiplanar reformation CT image showing distal end of the biliary stent perforating the ileal wall.

dominal free air, two pigtail stents still in situ in the cystogastrostomy, and migration of a pancreatic stent with duodenal perforation ( $\bullet$ Fig. 1).

Treatment consisted of endoscopic removal of the perforating stent and pigtail stents, percutaneous drainage of purulent ascites, intravenous antibiotics, bowel rest, and parenteral feeding. The patient recovered fully and was discharged from the hospital 14 days later.

The second case was that of a 71-year-old female patient with peritoneal dialysis, who underwent endoscopic retrograde cholangiopancreatography (ERCP) with biliary stenting for obstructive cholangitis. Three weeks later she developed bacterial peritonitis with Enterococcus sp., Klebsiella oxytoca, and Candida albicans. Abdominal CT scan revealed perforation of the ileum by the migrated biliary stent ( $\bullet$ Fig. 2 and 3). Because she developed septic shock, the biliary stent was surgically removed and primary repair of the ileal perforation was performed. The patient is still recovering.

The possibility of intestinal bowel perforation secondary to migrated biliary or pancreatic stent should be considered in patients presenting with abdominal pain after ERCP placement of stents. The choice between surgical vs. conservative management should be individualized and depends on the size and site of the perforation and any co-morbidity in the patient $[2,5]$.

Endoscopy_UCTN_Code_CPL_1AK_2AD

T. C. Seerden ${ }^{1}$, T. G. Moreels ${ }^{1}$,

R. A. Salgado ${ }^{2}$, S. M. Francque ${ }^{1}$,

P. P. Michielsen ${ }^{1}$, P. M. Parizel ${ }^{2}$,

\section{P. A. Pelckmans ${ }^{1}$}

Division of Gastroenterology and Hepatology, Antwerp University Hospital, Antwerp, Belgium

Division of Radiology, Antwerp University Hospital, Antwerp, Belgium

\section{References}

1 Miller G, Yim D, Macari M et al. Retroperitoneal perforation of the duodenum from biliary stent erosion. Curr Surg 2005; 62: $512-$ 515

2 Novacek G, Hormann M, Puig S et al. Duodenal perforation secondary to placement of a biliary endoprosthesis diagnosed by multislice computed tomography. Endoscopy 2002; 34: 351

3 Saranga BR, Rao P, Ghosh K. latrogenic duodenal perforations caused by endoscopic biliary stenting and stent migration: an update. Endoscopy 2006; 38: $1271-1274$

4 Lanteri R, Naso P, Rapisarda C et al. Jejunal perforation for biliary stent dislocation. Am J Gastroenterol 2006; 101: 908 - 909

5 Fatima J, Baron TH, Topazian MD et al. Pancreaticobiliary and duodenal perforations after periampullary endoscopic procedures: diagnosis and management. Arch Surg 2007; 142 : $448-454$

Bibliography

DOI $10.1055 / \mathrm{s}-2007-966961$

Endoscopy 2008; 40: E25

(C) Georg Thieme Verlag KG Stuttgart · New York ISSN 0013-726X

\section{Corresponding author}

\section{T. G. Moreels, MD, PhD}

Division of Gastroenterology and Hepatology

Antwerp University Hospital

Wilrijkstraat 10

2650 Antwerp

Belgium

Fax: +32-3-8214478

tom.moreels@uza.be 